\title{
PERANCANGAN SISTEM INFORMASI PENERIMAAN SISWA BARU DI SMAN UNGGULAN MH THAMRIN JAKARTA
}

\author{
Dewa Pratama S , Dian Nazelliana $^{2}$, Yunita Endra Megiati $^{3}$ \\ 1,2,3 Universitas Indraprasta PGRI \\ 11dewapratama09@gmail.com, 2dosen.dian@gmail.com, 33yunitaendra@gmail.com
}

\begin{abstract}
ABSTRAK
Permasalahan sistem pendaftaraan peserta didik pada SMAN Unggulan MH Thamrin Jakarta yang belum terkomputerisasi dan informasi data calon peserta didik yang belum terintegrasi dengan basis data yang berdampak pada sistem pelaporan yang masih manual. Maka dibuatnya suatu sistem pengelolaan infrastruktur pendaftaran peserta didik pada SMAN Unggulan MH Thamrin Jakarta berbasis web. Metode penelitian yang digunakan adalah metode Research \& Development yaitu suatu metode penelitian berdasarkan analisis kebutuhan dan uji keefektifan produk. Tujuannya agar dapat memudahkan semua kegiatan yang berhubungan dengan pendaftaran dapat menangani penginputan data tentang pendaftaran dengan cepat serta dapat di update dengan mudah dan memproses laporan sehingga memberikan hasil yang maksimal terhadap pihak sekolah dan orang tua peserta didik.Hasil dari penelitian ini adalah aplikasi penerimaan Siswa Baru berbasis web dengan menggunakan database MySQL.
\end{abstract}

Kata Kunci: Sistem Informasi Pendaftaran, Peserta Didik, Web

\begin{abstract}
Problems with the student registration system at SMAN Unggulan MH Thamrin Jakarta which has not been computerized and information on prospective student data that has not been integrated with the database has an impact on the reporting system which is still manual. So a web-based system for managing student registration infrastructure was made at SMAN MH Thamrin Jakarta. The research method used is the Research \& Development method, which is a research method based on needs analysis and product effectiveness testing. The goal is to make it easier for all activities related to registration to handle inputting data about registration quickly and can be updated easily and process reports so as to provide maximum results for the school and parents of students. The Result of this study is a web-based application for new student admissions using a MySQL database.
\end{abstract}

Key Word: Registration Information System, Students, Web

\section{PENDAHULUAN}

Perkembangan teknologi informasi saat ini semakin pesat, kebutuhan informasi dan pengelolahan data dalam banyak aspek kehidupan manusia menjadi suatu hal yang sangat penting. Perkembangan teknologi yang demikian pesat berdampak bagi seluruh kehidupan khususnya penyediaan informasi bagi suatu organisasi/instansi atau perusahaan yang membutuhkan sistem pengelolaan data secara cepat, tepat dan akurat. Untuk menunjang efektifitas, produktifitas dan efisiensi dalam satu organisasi/instansi atau perusahaan dalam menyelesaikan masalah manajemen.

Proses penerimaan siswa baru (PSB) di SMAN Unggulan MH Thamrin Jakarta selama ini masih bersifat manual, yaitu para calon siswa diharuskan datang ke SMAN Unggulan MH Thamrin Jakarta untuk proses registrasi, yakni; memasukkan data dengan menulis pada formulir pendaftaran, setelah data dituliskan dengan lengkap formulir pendaftaran diserahkan kepada panitia disertai berkas kelengkapannya. Data pendaftaran kemudian direkap oleh panitia penerimaan siswa baru kedalam komputer. Dalam proses rekap data ini panitia hanya menggunakan Software, Microsoft, Excel dan belum menggunakan sebuah sistem informasi, sehingga dalam proses input dan olah data membutuhkan waktu yang tidak sedikit dan menjadi tidak praktis.

Konsep dasar system merupakan suatu jaringan kerja dari prosedur yang berhubungan, untuk menyelesaikan suatu sasaran yang tertentu. Sistem adalah kumpulan elemen untuk mencapai suatu tujuan tertentu. Kemudian ada yang menyebutkan suatu sistem adalah agar mencapai suatu sasaran. "Sistem Informasi adalah kumpulan data yang terorganisir 
beserta tatacara penggunaannya yang lebih dari sekedar penyajian" (Hanif, 2009).

Sistem adalah kumpulan atau grup dari sub sistem/bagian/komponen apapun baik fisik ataupun non fisik yang saling berhubungan satu sama lain dan berkerja secara harmonis untuk mencapai satu tujuan tertentu. (Susanto, 2013)

Sistem adalah himpunan bagian atau komponen yang saling berhubungan secara teratur dan merupakan suatu keseluruhan. (Simarmata, 2020)

Informasi adalah suatu pertambahan dalam ilmu pengetahuan yang menyumbangkan kepada konsep kerangka kerja yang umum dan fakta-fakta yang diketahui. (Tyoso, 2016) Sistem Informasi merupakan kumpulan dari elemen-elemen yang berinteraksi untuk menghasilkan informasi yang berguna bagi penggunanya. (Nafiudin, 2019)

PHP adalah suatu bahasa pemrograman yang digunakan untuk menerjemahkan baris kode program menjadi kode mesin yang dapat dimengerti oleh komputer yang berbasis server-side yang dapat ditambahkan ke dalam HTML. (Supono, 2016)

MySQL adalah database server yang paling sering digunakan dalam pemograman PHP. MySQL digunakan untuk menyimpan data dalam database dan memanipulasi datadata yang diperlukan. (Buana, 2014)

Beberapa permasalahan antara lain pencatatan dan pendataan penerimaan siswa dilakukan secara manual menggunakan excel dan buku sehingga data hilang atau tercecer, Pencatatan bukti penerimaan siswa dan laporan penerimaan siswa masih dilakukan secara manual menggunakan excel, Pencatatan laporan penerimaan siswa dilakukan secara manual menggunakan excel dan dicatat menggunakan buku.

Berdasarkan pada uraian diatas maka didapatkan rumusan masalah sebagai berikut Bagaimana cara merancang sistem agar pencatatan dan pendataan penerimaan siswa baru lebih baik dan efisien?

Dan bagaimana cara menampilkan laporan hasil penerimaan siswa baru kepada siswa agar dapat dilihat sewaktu waktu tanpa harus datang ke sekolah?
Adapun tujuan penelitian adalah sebagai berikut, Membuat sistem informasi penerimaan siswa baru di sekolah SMAN Unggulan MH Thamrin Jakarta, dengan sistem informasi yang di bangun dan di kembangkan dengan PHP dan database $M Y S Q L$ agar proses pencatatan data penerimaan siswa baru lebih baik sehingga dapat menggunakan waktu secara efisien untuk mengerjakan tugas lain, serta proses cetak laporan penerimaan siswa baru terupdate, sehingga dapat memberikan laporan kepada Kelapa Sekolah dengan cepat dan terstruktur rapih.

\section{METODE PENELITIAN}

Dalam penelitian ini, penulis menggunakan metode penelitian Research and Development, yaitu sebagai metode penelitian yang secara sengaja sistematis, bertujuan, diarahkan untuk mencari atau menemukan, merumuskan, memperbaiki, mengembangkan, menghasilkan, menguji keefektifan produk, model, metode/strategi/cara jasa, prosedur tertentu yang lebih unggul, baru, efektif, produktif, dan bermakna. (Sugiyono, 2016)

Adapun metode pengumpulan data yang penulis lakukan umtuk penelitian sebagai berikut.

\section{Observasi}

Penulis mempelajari dan mengamati sistem pendataan Penerimaan siswa baru dan bagian administrasi serta keterkaitan antara subsistem dengan yang lainnya pada bulan September 2020 sebelum melakukan penulisan tugas akhir ini.

2. Interview

Penulis melakukan wawancara di SMAN Unggulan MH Thamrin Jakarta dan bertemu langsung dengan Muhammad Ramzy selaku Guru pada bagian Administrasi tersebut.

3. Studi Literatur

Mempelajari buku-buku literatur mengenai analisis dan mendesain sebuah system, serta buku-buku pemrograman Java menggunakan $P H P$ untuk mengintegrasikannya dengan $M y S Q L$, dan mencari dan mempelajari informasi melalui internet yang berhubungan dengan perancangan aplikasi Penerimaan siswa. 


\section{HASIL DAN PEMBAHASAN}

Proses berjalan atau serangkaian proses pendaftaran PPDB yang terjadi pada SMAN Unggulan M.H Thamrin Jakarta masih menggunakan cara manual dengan pembelian formulir dan melalui wawancara secara langsung. Berikut gambaran sistem yang berjalan pada SMAN Unggulan M.H Thamrin Jakarta dalam bentuk Unified Modeling Language (UML).

\section{Activity Diagram yang Berjalan}

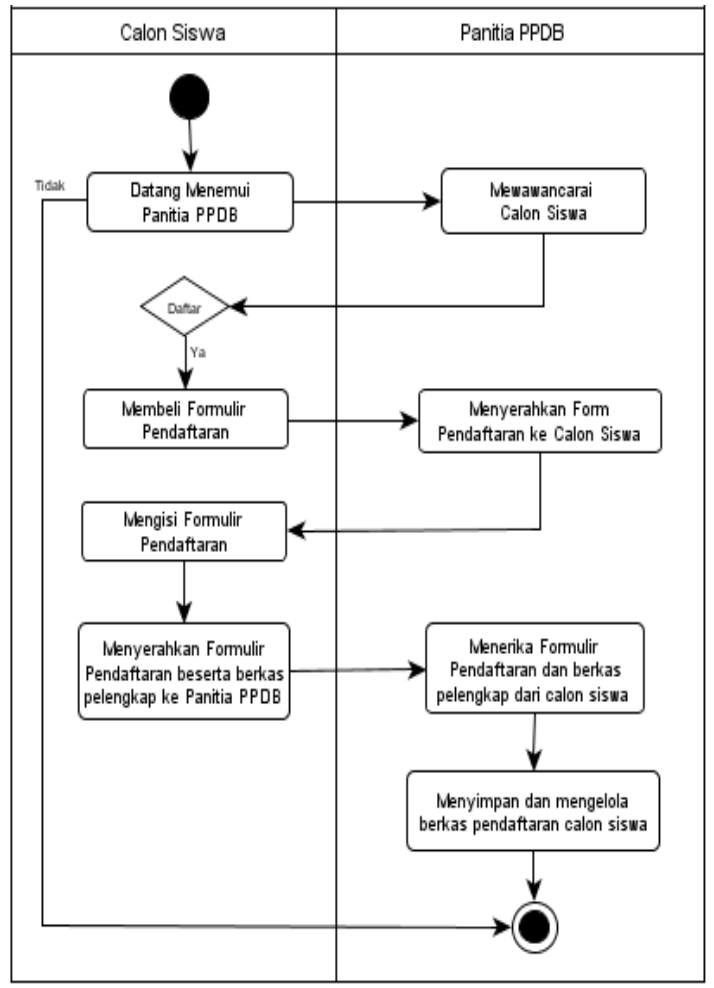

Gambar 1. Activity Diagram PPDB yang Sedang Berjalan

Calon siswa datang menemui panitia PPDB yang sedang bertugas, setelah itu panitia akan mewawancarai calon siswa tersebut. Jika siswa bersedia untuk mendaftar, calon siswa membeli formulir pendaftaran dari panitia untuk di isi dan diserahkan kembali beserta berkas pelengkap ke panitia PPDB. Setelah formulir pendaftaran dan berkas pelengkap diterima oleh panitia, lalu panitia akan menyimpan dan mengelola berkas tersebut untuk diproses lebih lanjut.
Dekomposisi Fungsi Sistem yang Berjalan

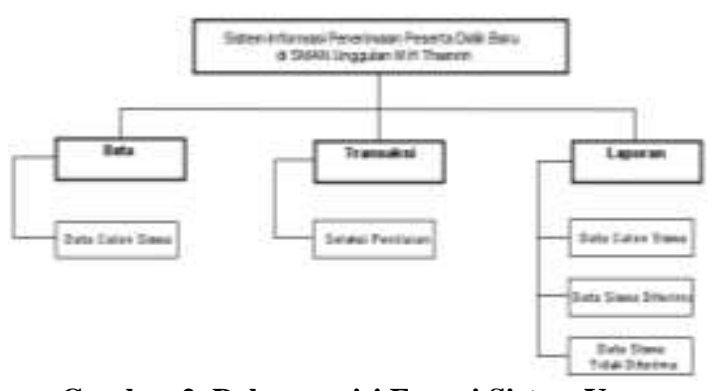

Gambar 2. Dekomposisi Fungsi Sistem Yang Sedang Berjalan.

\section{Dekomposisi Fungsi Sistem Yang Diusulkan}

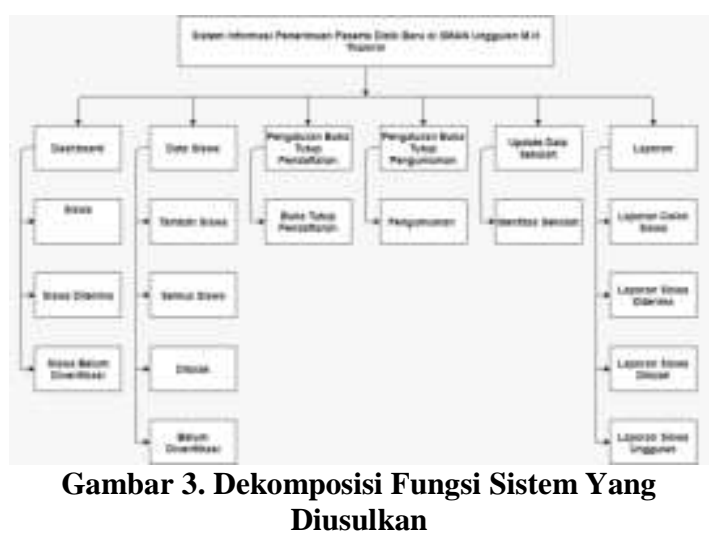

Unified Modeling Language (UML) Yang Diusulkan

$U M L$ adalah salah satu standar bahasa yang banyak digunakan didunia industri untuk mendefinisikan requirement, membuat analisis dan desain, serta menggambarkan arsitektur dalam pemrograman berorientasi objek. (Rosa, 2015)

\section{Use Case Diagram Yang Diusulkan}

Use Case adalah diagram yang harus di buat pertama kali saat permodelan perangkat lunak berorientasi objek dilakukan. (Feri Sulianta, 2015)

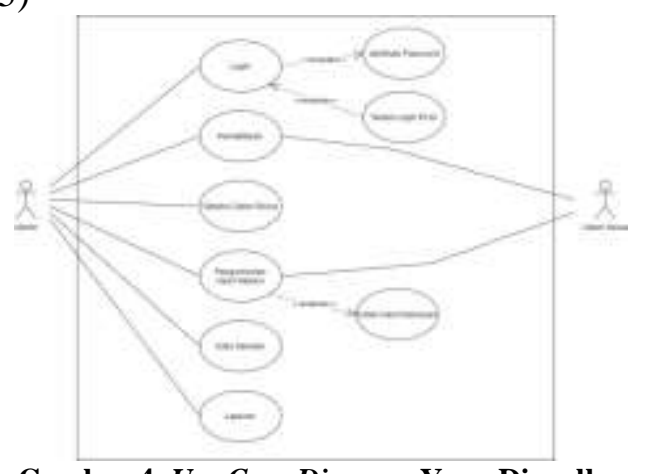

Gambar 4. Use Case Diagram Yang Diusulkan 


\section{Class Diagram Yang Diusulkan}

Class diagram adalah diagram yang digunakan untukmempresentaksikan kelas, komponen-komponen kelas dan hubungan antara masing-masing kelas. (Mulyani, 2016)

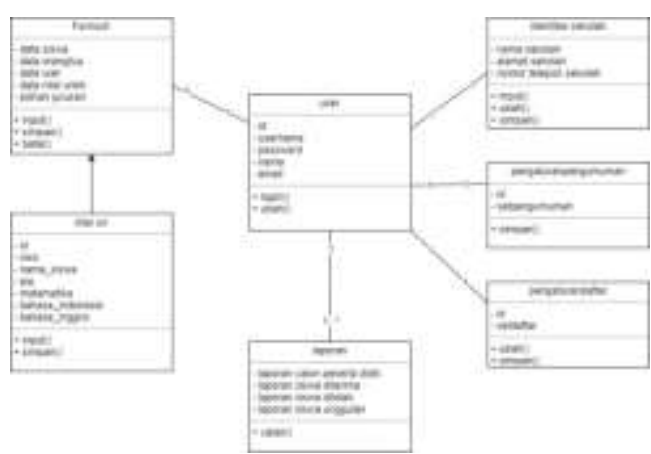

Gambar 5. Class Diagram Yang Diusulkan

\section{Activity Diagram Yang Diusulkan}

Activity diagram menggambarkan aliran kerja atau aktifitas dari sebuah sistem atau proses bisnis atau menu yang ada pada perangkat lunak. Diagram aktifitas menggambarkan aktifitas sistem bukan apa yang dilakukan oleh aktor. (Sukamto, 2014)

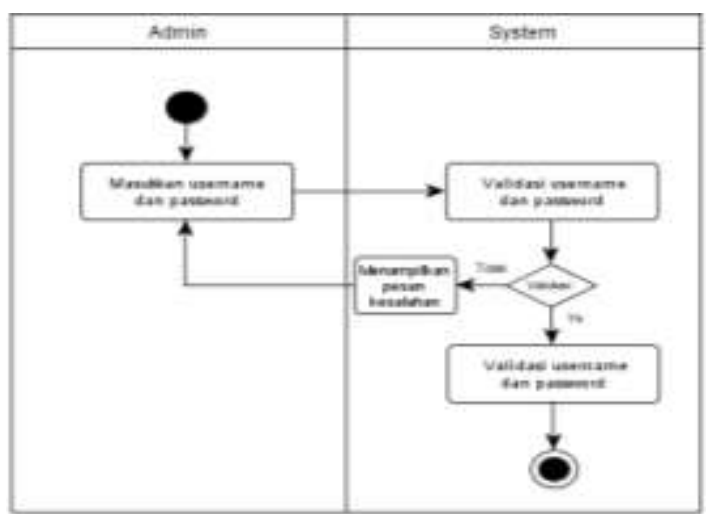

Gambar 6. Activity Diagram Login yang Diusulkan

Admin melakukan login, kemudian sistem akan memverifikasi username dan password yang di masukan user sebagai admin.

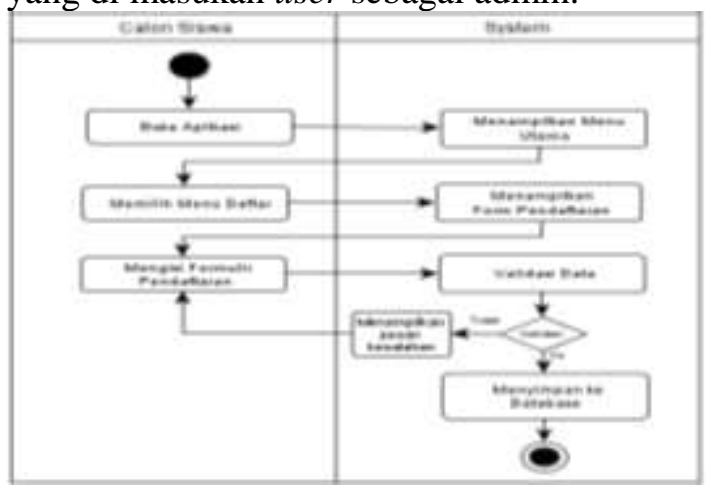

Gambar 7. Activity Diagram Pendaftaran Yang Diusulkan
Calon Siswa memilih menu Daftar kemudian mengisi formulir pendaftaran, menyimpan kedalam system agar data tersimpan kedalam database.

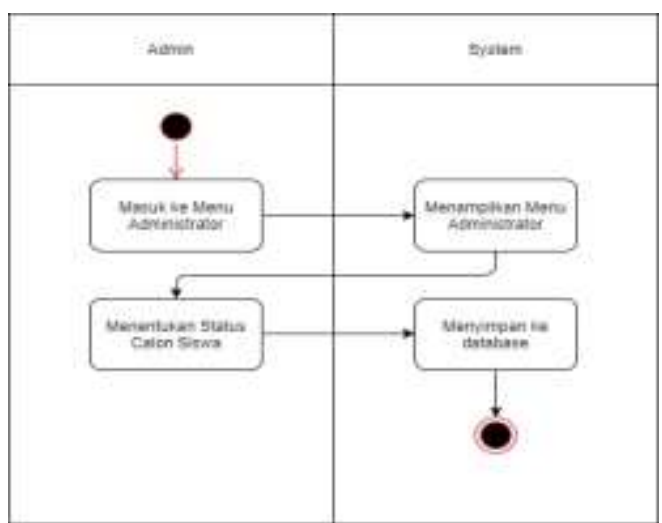

Gambar 8. Activity Diagram Seleksi Calon Siswa yang Diusulkan

Admin melakukan seleksi data calon siswa yang sudah tersimpan dan menentukan status kelulusan calon siswa lalu menyimpan data tersebut kedalam database.

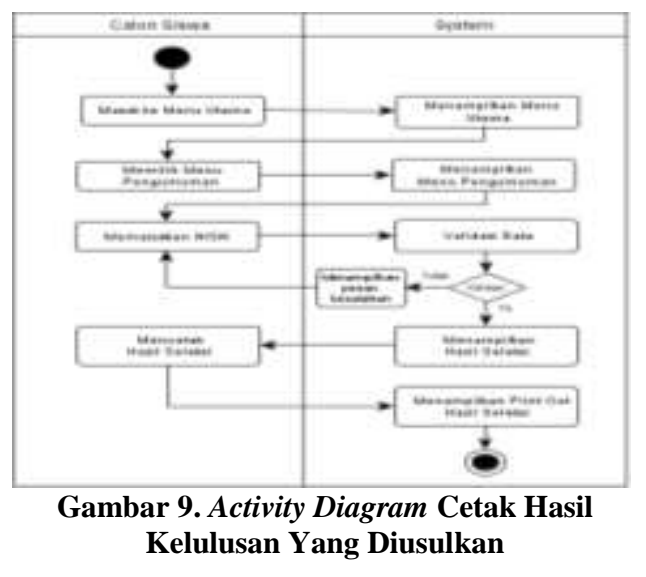

Calon Siswa memilih menu pengumuman kemudian mencetak hasil kelulusan dengan cara memasukan NISN.

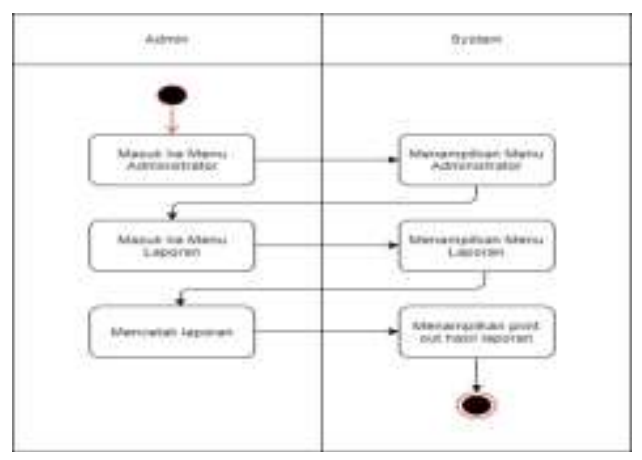

Gambar 10. Activity Diagram Laporan yang Diusulkan 
Admin membuka halaman administrator lalu memilih Menu Laporan untuk mencetak laporan.

\section{ERD (Entity Relationship Diagram)}

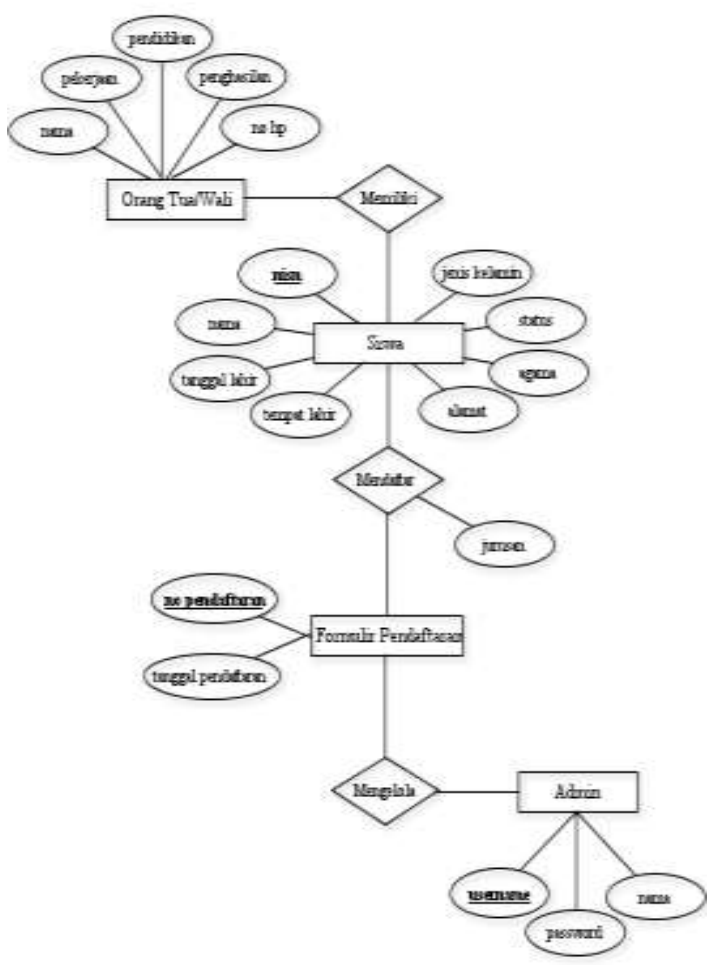

Gambar 11. ERD (Entity Relationship Diagram) Yang Diusulkan

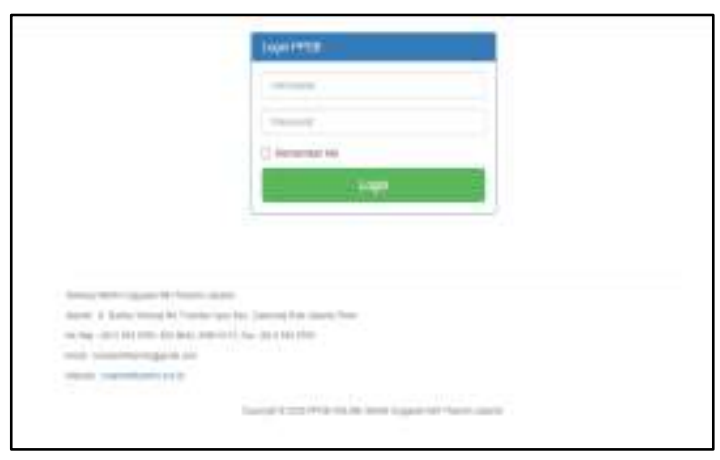

Gambar 12. Tampilan Login

Tampilan login digunakan untuk pengguna sebagai akses masuk menuju program agar pengguna dapat mengakses semua menu yang ada di aplikasi penerimaan peserta didik baru SMAN Unggulan M.H Thamrin Jakarta. Menu login ini terdapat ID dan password pengguna yang telah tersimpan di database agar tidak ada orang lain yang bisa mengakses program ini sehingga keamanan tetap terjaga dengan baik.

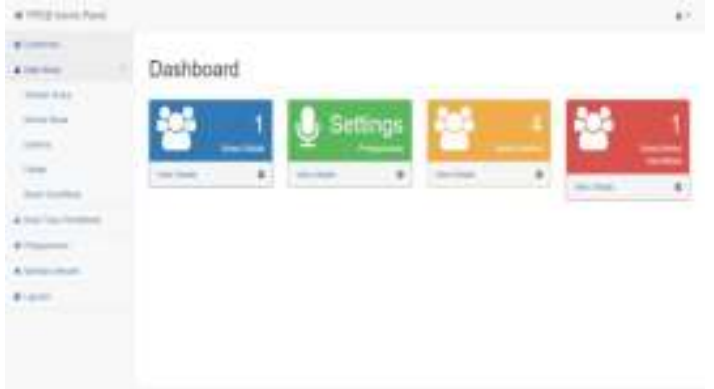

Gambar 13. Tampilan Menu Untuk Admin

Tampilan diatas adalah tampilan layar menu utama, tampilan ini terbuka setelah kita berhasil memasukan ID dan password pengguna dengan benar. Tampilan ini mempunyai 5 menu yang dapat diakses pengguna yaitu Data Siswa, Data Buku Tutup Pendaftaran, Pengumuman, Update Sekolah, Laporan serta tombol keluar jika pengguna ingin mengakhiri program ini.

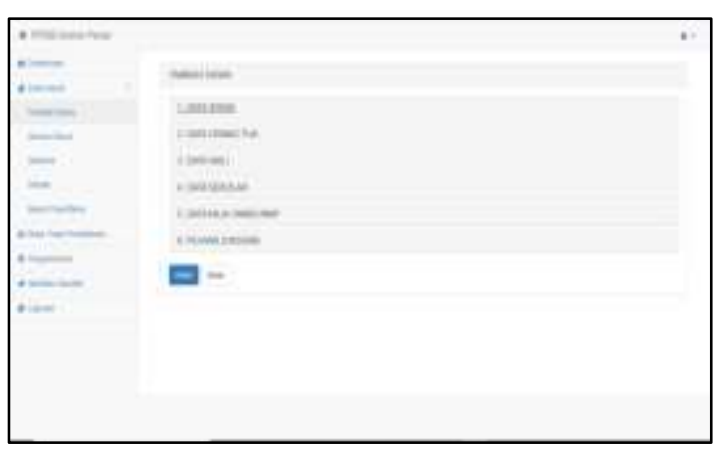

Gambar 14. Tampilan Tambah Siswa oleh Admin

Tampilan diatas adalah tampilan menu Data Siswa yang berfungsi untuk menginput dan mengolah data siswa yaitu berupa data siswa, data orang tua , data wali, data sekolah, data nilai unbk dan pilihan jurusan.

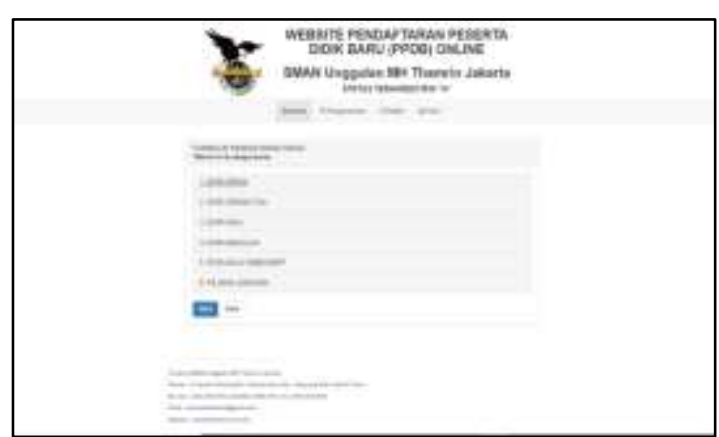

Gambar 15. Tampilan Menu Daftar

Tampilan diatas adalah tampilan menu daftar yang berfungsi untuk mengisi formulir pendaftaran siswa. 


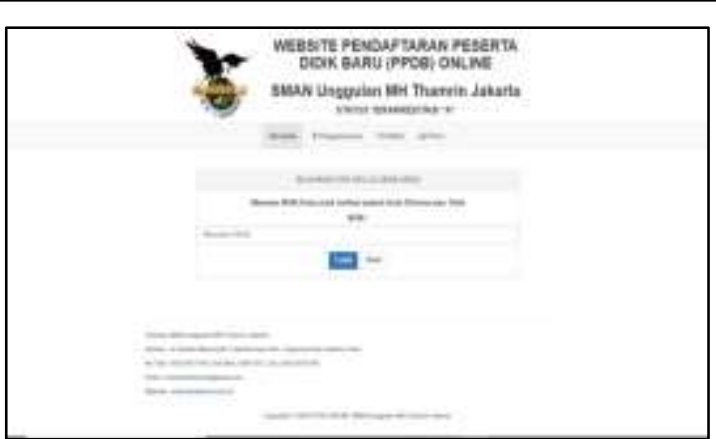

Gambar 16. Tampilan Menu Cetak Pengumuman

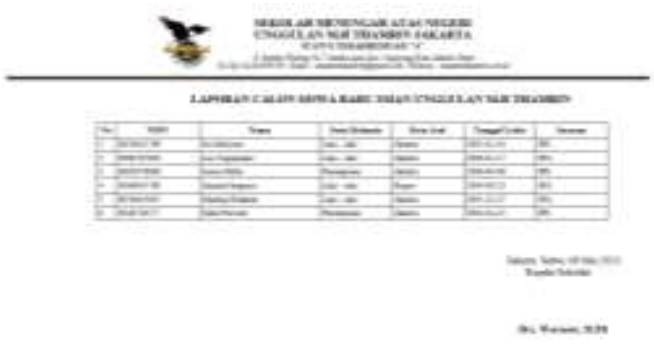

Gambar 17. Tampilan Laporan Semua Siswa

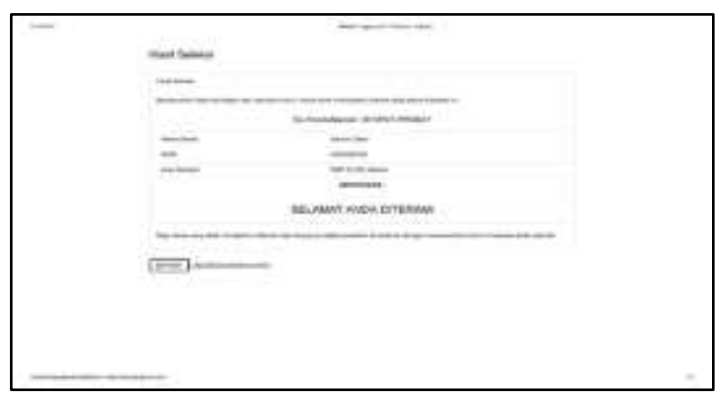

Gambar 18. Tampilan Keluaran Diterima

\section{SIMPULAN DAN SARAN}

Berdasarkan hasil penelitian tentang sistem pengelolaan data penerimaan siswa baru yang sedang berjalan pada saat sekarang ini dan melakukan perbandingan dengan rancangan sistem informasi baru yang menggunakan Mysql serta bahasa pemograman PHP, maka dapat disimpulkan bahwa Proses penerimaan siswa baru yang telah berjalan sebelum penulis membuat aplikasi ini masih kurang baik, karena dilakukan secara manual. Maka dengan adanya aplikasi ini, sekolah dapat melakukan penambahan data, pengeditan data serta penyimpanan data siswa baru secara terpadu tanpa adanya data yang ter-skip, hilang ataupun salah data.

Dengan adanya pembangun sebuah sistem informasi yang baru dapat mempermudah untuk penerimaan siswa baru di sekolah SMAN Unggulan MH Thamrin Jakarta.
Membuat sebuah aplikasi menggunakan $P H P$ dan database MYSQL Dapat membantu untuk menghasilkan sistem informasi dalam keamanan dan keakuratan suatu data dapat terjaga dan proses lebih cepat dan tepat. Dengan cara mengimplementasikannya sistem informasi penerimaan siswa baru di SMAN Unggulan MH Thamrin Jakarta dapat meningkatkan mutu disekolah tersebut.

Berdasarkan simpulan diatas, tentu saja banyak kekurangan dan kelemahan. Oleh karena itu, terdapat beberapa hal yang perlu diperhatikan untuk membantu dalam pengembangan sistem selanjutnya, dalam mengelola database program yang harus diperhatikan oleh admin yaitu agar sering memback-up database supaya data selalu aman apabila terjadi kerusakan software atau hardware yang tidak diinginkan pada server penyimpan database.

Dari saran-saran yang telah dikemukakan, diharapkan sistem informasi yang baru ini dapat bermanfaat bagi pihak-pihak yang akan menggunakan maupun yang akan melakukan pengembangan lebih lanjut, sehingga hasil yang dicapai dapat lebih baik, maksimal, dan optimal.

\section{DAFTAR PUSTAKA}

Buana. (2014). Aplikasi XAMPP. Jakarta: Andi.

Feri Sulianta, d. F. (2015). Teknik Hebat Merancang Aplikasi Instan dan Berkualitas. Jakarta: PT. Elex Media Komputindo.

Mulyani, S. (2016). Sistem Informasi Manajemen Rumah Sakit: Analisis dan Perancangan. Bandung: Abdi Sistematika.

Nafiudin. (2019). Sistem Informasi Manajemen. Surabaya: Qiara Media.

Rosa, D. S. (2015). Rekayasa Perangkat Lunak Terstruktur dan Berorientasi Objek. Bandung: Informatika Bandung.

Simarmata, J. (2020). Pengantar Manajemen Sistem Informasi. Medan: Yayasan Kita Menulis.

Sugiyono. (2016). Metode Penelitian Kuantitatif, Kualitatif dan $R \& D$. Bandung: Alfabeta. 
Sukamto, d. S. (2014). Rekayasa Perangkat Lunak Terstruktur Dan Berorientasi Objek. Bandung: Informatika Bandung.

Supono, d. P. (2016). Pemrograman Web dengan menggunakan PHP dan Framework Codeigniter. Yogyakarta: Deepublish.

Tyoso, J. S. (2016). Sistem Informasi Manajemen. Yogyakarta: Deepublish.

Riko., Agustian, Fajar., \& Norma, Pravitasari. (2021). Perancangan Sistem Informasi Penerimaan Siswa Baru Di Sman Unggulan Mh Thamrin Jakarta. Jurnal semnas ristek (Seminar Nasional Riset dan Teknologi), 5(1), 165.

Sofyana, Tasya. (2021). Perancangan Sistem Pendaftaran Siswa Pada Bimbingan Belajar Jendela Ilmu Berbasis Java Netbeans. Jurnal semnas ristek (Seminar Nasional Riset dan Teknologi), 5(1),699.

Nurul Muthmainnah, Nurul., Sunoto, Imam,. \& Nur Huda,. Didik. (2021). Perancangan Sistem Informasi Penerimaan Siswa Baru Dan Pembayaran Pada Tkit Al Muwahhidiin. Jurnal semnas ristek (Seminar Nasional Riset dan Teknologi), 5(1),433. 